\title{
PÓS-LICENCIAMENTO AMBIENTAL: ONDE FORAM APLICADOS OS R\$1OO MILHÕES DOS PLANOS BÁSICOS AMBIENTAIS DAS HIDRELÉTRICAS INSTALADAS NO ESTADO DO AMAPÁ?
}

\author{
ENVIRONMENTAL POST-LICENSING: WHERE WERE INVESTED THE \\ R\$100 MILLION DESTINED TO BASIC ENVIRONMENTAL PLANS OF \\ HYDROELECTRIC PLANTS IN THE STATE OF AMAPÁ?
}

Marco Antonio Chagas ${ }^{1}$

http://lattes.cnpq.br/8349011053672474 https://orcid.org/0000-0002-4792-9154

\section{Ricardo Ângelo Pereira de Lima \\ http://lattes.cnpq.br/1993748824383678 https://orcid.org/0000-0002-3532-422X}

\section{Marcelo José de Oliveira ${ }^{3}$ \\ http://lattes.cnpq.br/0612708881662162 \\ https://orcid.org/0000-0002-2460-7259}

Recebido em: 16/08/2019

Aceito em: 25/11/2019

\begin{abstract}
RESUMO: Um dos desafios da política ambiental brasileira é a revisão do Licenciamento Ambiental. A principal proposta em tramitação tem sido questionada quanto à sua eficiência, com críticas de retrocessos quando analisada sob a ótica das boas práticas internacionais. Este artigo elabora o conceito de Pós-Licenciamento Ambiental como ênfase na importância das etapas de acompanhamento e de comprovação de resultados das ações vinculadas às licenças ambientais (prévia, de instalação e de operação). O conceito é proposto com base em análise dos casos das hidrelétricas de Ferreira Gomes e de Cachoeira Caldeirão no Amapá. Entre os principais achados, estima-se que recursos da ordem de R \$100 milhões foram orçados para os Planos Básicos Ambientais, com resultados inexpressivos ou mesmo inexistentes diante das informações analisadas. A conclusão aponta para a necessidade de melhoria da eficiência do instrumento, consubstancia-
\end{abstract}

\footnotetext{
${ }^{1}$ É bacharel em Geologia pela Universidade Federal do Pará. Mestre em Desenvolvimento Sustentável pelo Centro de Desenvolvimento Sustentável da Universidade de Brasília e Doutor em Desenvolvimento Socioambiental pelo Núcleo de Altos Estudos Amazônicos da Universidade Federal do Pará. Atualmente é professor do Curso de Graduação em Ciências Ambientais e do Mestrado em Desenvolvimento Regional da Universidade Federal do Amapá. E-mail: marco.chagas@uol.com.br.

${ }^{2}$ É bacharel e licenciado em Geografia pela Universidade Federal do Pará. Mestre em Geografia Humana pela Universidade Autónoma de Barcelona e Doutor em Geografia Humana pela Universidade Autónoma de Barcelona e em Géographie et Aménagement pela Universidade de Toulouse II (Le Mirail). Atualmente é professor do Curso de Graduação em Geografia e dos mestrados em Geografia e em Desenvolvimento Regional da Universidade Federal do Amapá. E-mail: ricardoangelo_pereira@yahoo.es.

${ }^{3}$ É bacharel em Geologia pela Universidade Federal do Pará Mestre em Geologia e Geoquímica pela Universidade Federal do Pará e Doutor em Desenvolvimento Socioambiental pelo Núcleo de Altos Estudos Amazônicos da Universidade Federal do Pará. Atualmente é professor do Curso de Graduação em Ciências Ambientais da Universidade Federal do Amapá. E-mail: geomarcelooliveira@gmail.com.
} 
da em maior rigor no pós-licenciamento e em boas práticas de gestão ambiental associadas.

Palavras-chave: Pós-licenciamento Ambiental. Gestão Ambiental. Usinas Hidrelétricas. Amapá.

ABSTRACT: One of the challenges of Brazil's environmental policy is a necessary review of the Environmental Licensing. The efficiency of the main ongoing project has been questioned and some critics mention regression when compared to the good international practices. This article develops the concept of "Environmental Post-Licensing", which stresses the importance of monitoring the results of the actions related to environmental licenses (previous, implementation and operational actions). The concept is based on the analysis of the cases of two bydroelectric plants (Ferreira Gomes and Cachoeira Caldeirão) in the state of Amapá. Among the main findings, it is estimated that about $\mathrm{R} \$ 100$ million were destined to Basic Environmental Plans, whose results were inexpressive or even inexistent. The conclusion suggests the necessity of improving the efficiency of the instrument, with greater rigour in the post-licensing and associated good environmental management practices.

Keywords: Environmental Post-Licensing. Environmental Management. Hydroelectric Plants. Amapá.

\section{INTRODUÇÃO}

O Brasil sempre pautou o debate sobre desenvolvimento sem considerar os significados de natureza e de meio ambiente, desde percepções mais existencialistas da ecologia profunda até possibilidades de sua dominação subjugada de desenvolvimento equilibrado, includente, sustentável, entre outros adjetivos modistas.

No campo circunscrito às derivações desenvolvimentistas e em pleno regime político de ditadura militar (1964-1985), o Governo Brasileiro concebeu a Política Nacional do Meio Ambiente - PNMA (Lei no 6.938/81), incluindo o Licenciamento Ambiental e a Avaliação de Impacto Ambiental - AIA entre os 13 instrumentos para sua implementação.

Alguns desses instrumentos foram submetidos a regulamentações e passaram a forjar a estrutura institucional pública de meio ambiente. Outros instrumentos foram praticamente esquecidos ou desconsiderados. No caso do licenciamento e da AIA, o amparo legal se efetivou em matéria constitucional (artigo 225), em resoluções do Conselho Nacional do Meio Ambiente - CONAMA (nos 01/1986 e 237/97) e em lei complementar (140/2011).

Vários estudos sobre licenciamento ambiental têm demonstrado a deficiência desse instrumento no efetivo controle dos impactos socioambientais, principalmente dos grandes empreendimentos, como as hidrelétricas implantadas na Amazônia (CASTRO et al., 2014; FEARNSIDE, 2015; 2016).

Desde 2004 tramita no Congresso Nacional uma proposta de Lei Geral do Licenciamento Ambiental (Projeto de Lei no 3729/2004), a qual traz algumas novidades promissoras, sobretudo relacionadas à gestão da informação. Todavia, no seu conjunto possui diversos problemas conceituais, contradições, omissões e dissonâncias em relação às boas práticas internacionais (FONSECA et al., 2019).

Este artigo desdobra o entendimento do licenciamento, consubstanciado no conceito de "Pós-Licenciamento Ambiental". Em princípio, o referido conceito se faz entender a partir das relações sinergéticas e participativas que convergem para resultados enunciados em forma de boas práticas institucionais de gestão ambiental. 
O licenciamento das hidrelétricas Ferreira Gomes e Cachoeira Caldeirão no estado do Amapá, com ênfase nos Planos Básicos Ambientais - PBAs, permite situar analiticamente o conceito de Pós-Licenciamento Ambiental e, dessa forma, propor ajustes institucionais para além dos vínculos normativos propostos no Projeto de Lei que trata do instrumento da política ambiental.

\section{METODOLOGIA}

O artigo desenvolve o conceito de Pós-Licenciamento Ambiental, metodologicamente formulado com base em experiência empírica dos autores e em análise crítica de boas práticas do licenciamento ambiental praticado no Brasil. Afere-se a fundamentação teórica com base na revisão da literatura que trata de iniciativas de boas práticas que objetivam a sistematização de dados sobre licenciamento ambiental, a disponibilização ao acesso público e a revisão normativa consubstanciada na proposta de uma lei geral (Projeto de Lei no $3729 / 2004)$.

A opção pelo estudo de caso deve-se a um conjunto de fatos genéricos que, de alguma forma, evidenciam aspectos técnicos e políticos relacionados à implantação de empreendimentos de significativos impactos ambientais na Amazônia. Para tal, relata-se o processo de Licenciamento Ambiental de duas hidrelétricas no Amapá, consubstanciado nos compromissos vinculados às licenças emitidas, principalmente a de instalação. Buscou-se uma análise crítica dos Programas Socioambientais - PSAs constantes nos Programas Básicos Ambientais - PBAs das hidrelétricas.

A pesquisa se concentrou em documentos que comunicam as ações ambientais implementadas pelos empreendedores, como: sites das empresas responsáveis pelas hidrelétricas, relatórios de monitoramento e de sustentabilidade, entre outros. Essas informações constituem elementos de análises que dão sustentação conceitual ao Pós-Licenciamento Ambiental.

É importante destacar que o órgão ambiental licenciador do estado do Amapá não disponibiliza informações on-line sobre os processos de Licenciamento Ambiental. O Amapá não cumpre a lei da transparência ambiental (Lei no 10.650/2003), com inserção no site institucional limitada a algumas licenças emitidas no período de 2014 a 2018 (IMAP, 2019). Dessa forma, alguns pareceres processuais foram capturados de arquivos diversos, tanto dos autores, quanto de colaboradores que também pesquisam sobre o tema.

Sobre os empreendimentos hidrelétricos analisados (Ferreira Gomes e Cachoeira Caldeirão) ${ }^{4}$, estes foram implantados na bacia do Rio Araguari, entre os municípios de Ferreira Gomes e Porto Grande, no estado do Amapá. Neste trecho do rio existe também uma hidrelétrica em operação desde a década de 1970, a Coaracy Nunes (Figura 1).

${ }^{4}$ A hidrelétrica Ferreira Gomes entrou em operação em 2014 e a hidrelétrica Cachoeira Caldeirão em 2016. 
Figura 1 - Hidrelétricas no Rio Araguari, município de Ferreira Gomes, Amapá

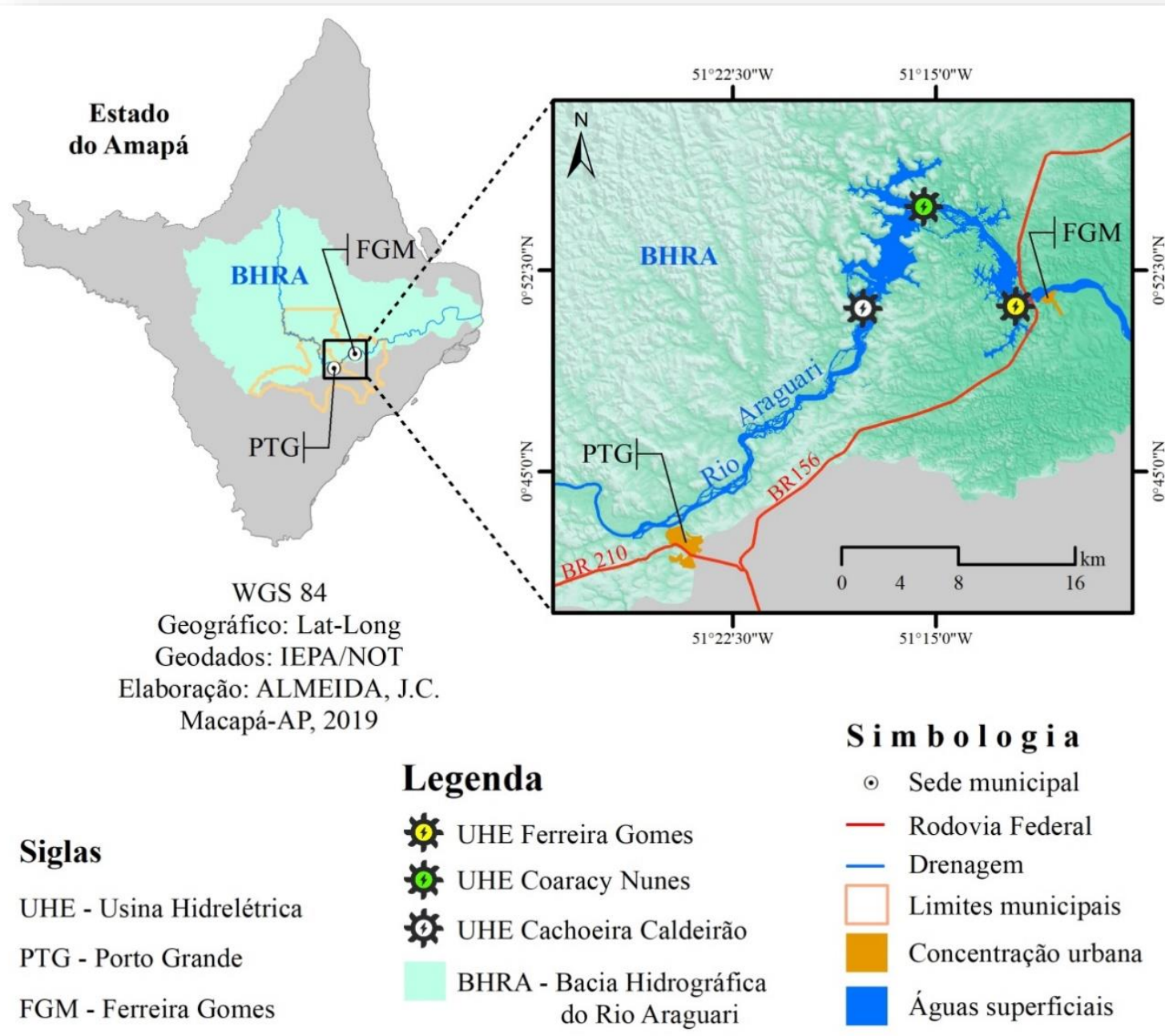

Fonte: Elaborado pelo geografo Jodson Almeida.

A bacia hidrográfica do Rio Araguari corresponde a 1/3 da área total do estado do Amapá (45.000 $\mathrm{km}^{2}$ ) e constitui o principal sistema de regulação do clima e da biodiversidade regional. O curso inferior do rio é caracterizado por uma extensa planície que deságua no Oceano Atlântico. Este trecho do rio vem apresentando intensas modificações hidrodinâmicas, com causas que se confrontam entre explicações de ordem natural (evolução geológica de rio de planície) e antrópica (mineração, hidrelétrica, bubalinocultura) (SANTOS, 2006; 2012; CHAGAS; SANTOS; CUNHA, 2015; SANTOS; CUNHA; CUNHA, 2017).

\section{CONCEITO DE PÓS-LICENCIAMENTO AMBIENTAL E SUA PROBLE- MATIZAÇÃo}

Objetivamente, o Pós-Licenciamento Ambiental se refere às etapas de acompanhamento dos compromissos vinculados aos processos de emissão das licenças: Prévia - LP, de Instalação - LI e de Operação - LO, com foco em desempenho e resultados. Trata-se dos desdobramentos dos estudos ambientais, das deliberações das audiências públicas, das condicio- 
nantes das licenças e outros acordos voluntários, respeitada a discricionariedade da autoridade ambiental competente.

No atual Sistema de Licenciamento Ambiental, uma vez comprovado o cumprimento dos condicionantes das licenças ou de sua implementação, avança-se para as etapas subsequentes do Licenciamento Ambiental Trifásico adotado no Brasil (LP, LI e LO). O objetivo é comprovar a viabilidade socioambiental da atividade ou empreendimento submetido ao Licenciamento Ambiental, de modo que a melhoria contínua do processo resulte em condições favoráveis à elaboração de um Plano de Gestão Ambiental.

O Pós-Licenciamento Ambiental resulta no Plano de Gestão Ambiental, construído como contributo de determinada atividade econômica ao desenvolvimento sustentável da região em que opera. Diferencia-se parcialmente do entendimento do Banco Mundial (2008), de Sánchez (2013) e de Ribeiro (2015) que o vinculam às etapas de acompanhamento/resultado das ações de controle dos impactos e não como sinergias que moldam um processo favorável ao Plano de Gestão Ambiental de longo prazo.

Por Plano de Gestão Ambiental subtende-se um conjunto de ações públicas e privadas que em complementaridade convergem para evitar impactos negativos, minimizá-los ou compensá-los, bem como potencializar os impactos positivos. O plano potencializa a credibilidade de determinada atividade ou empreendimento, sendo construído desde as etapas de planejamento e prolongando-se por todo ciclo de vida do projeto ou até sua desativação, com foco na sustentabilidade.

O Pós-Licenciamento Ambiental é um campo negligenciado nas rotinas dos órgãos oficiais de controle ambiental e de frágil percepção por parte da população diretamente afetada e/ou interessada. A gênese desses problemas é cíclica. Inicia-se na elaboração do escopo ou termo de referência dos estudos ambientais, estendendo-se aos procedimentos metodológicos de identificação e avaliação dos impactos, às propostas de ações de controle dos impactos e, fundamentalmente, ao processo de acompanhamento e de avaliação dos resultados (BARRETO, 2012; SÁNCHEZ, 2013; RIBEIRO, 2015; ALMEIDA; MONTAÑO, 2017).

Acentua-se a problemática diante da ilusória expectativa da população de que as deficiências da gestão pública serão assumidas pelo empreendedor. Sob esse aspecto, é comum a imposição de exigências de condicionantes no licenciamento ambiental desvinculadas dos impactos. Este é o principal motivo da resistência privada quanto à participação da população, pois a ausência de políticas públicas, principalmente em regiões carentes, coloca o PósLicenciamento Ambiental em mera condição de um resultado maniqueísta a ser estampado na parede da empresa como sinal verde do poder público para operar.

Em sua face mais perversa, ingerências políticas transformam o Pós-Licenciamento Ambiental num balcão de negócios, onde os impactos são negligenciados diante de acordos de gabinete pactuados diretamente entre o empreendedor e a autoridade ambiental. Nesses casos, ainda predominantes no Brasil, as populações afetadas pelos impactos são colocadas à margem do processo e o Pós-Licenciamento Ambiental tende a transformar-se em conflitos permanentes, quase sempre judicializados, com resultados em desfavor dos impactados por razões óbvias (BURSZTYN; BURSZTYN, 2012, p. 509).

A participação e a transparência são questões positivas e favoráveis ao Pós-Licenciamento Ambiental e a uma possível transição para o Plano de Gestão Ambiental. As experiências apontam como boas práticas: i) informatização e disponibilização on-line dos processos em websites; ii) implantação de centrais de atendimento (call center); e iii) publicação de relatórios 
de comunicação (FONSECA; RESENDE, 2016). Fonseca et al. (2019) fazem referência a questões transversais relacionadas à eficiência administrativa, participação pública e credibilidade.

A problematização está centrada em creditar conceitualmente o Pós-Licenciamento Ambiental e em rastrear algumas boas práticas que podem potencializá-lo rumo à construção de um efetivo Plano de Gestão Ambiental. O estudo de caso do Licenciamento Ambiental de Hidrelétricas no Amapá fundamenta a crítica argumentativa em favor do Pós-Licenciamento Ambiental e evidencia fatos para maior verificação a posteriori.

\section{BOAS PRÁTICAS DE LICENCIAMENTO AMBIENTAL ADOTADAS NO BRASIL - A IMPORTÂNCIA DA TRANSPARÊNCIA AMBIENTAL}

O Pós-Licenciamento Ambiental é um conceito novo que somente tem sentido se estiver associado a um conjunto de ações sistematizadas e integradas que resulte em melhoria contínua do processo de licenciamento e na consequente construção de um Plano de Gestão Ambiental. Um dos alicerces deste processo é a transparência.

A falta de informação sistematizada e de transparência dos processos de Licenciamento Ambiental no Brasil são sintomas de um mesmo mal que afeta a administração pública brasileira em diferentes setores e escalas de atuação. O problema, entretanto, não reside em limitações tecnológicas, mas na descomplexização do dilúvio de informações geradas e das estratégias de sistematização para garantias de direitos ao acesso do cidadão.

Em tempos de crise da democracia representativa, a informação bem organizada e disseminada constitui um elemento essencial para outras formas de democracias ou democracias complementares, como a participativa e a comunitária. Nesse sentido, alinha-se a tese de que a garantia da transparência é insumo instrumental para a liberdade (SEN, 2010).

Entre as iniciativas pela transparência, a Carta da Terra, por exemplo, documento declaratório dos princípios para o desenvolvimento sustentável global, estabelece em seu ponto 13 que trata da democracia: "Fortalecer as instituições democráticas em todos os níveis e proporcionar-lhes transparência e prestação de contas no exercício do governo, participação inclusiva na tomada de decisões e acesso à justiça" (DOWBOR, 2004, p. 6).

No âmbito da iniciativa denominada "Parceria para Governo Aberto" ou OGP (do inglês Open Government Partnership), o compromisso 15, do 3o Plano de Ação do Brasil, fortalece o compromisso do governo para "transparência ativa" em matéria de meio ambiente, o que de certa forma impulsiona a Lei no 12.527/2011, conhecida como Lei de Acesso à Informação LAI.

O Plano de Dados Abertos do Ministério do Meio Ambiente - PDA/MMA, vinculado aos compromissos setoriais do Governo Brasileiro com as iniciativas OGP e LAI, registra o atual estágio de abertura de dados ambientais sistematizados para diferentes tipos de usuários e projeta ações para abertura de novos dados (MMA, 2017).

Segundo o PDA/MMA, atualmente três sistemas de dados ambientais estão disponibilizados em formato aberto para consulta parametrizada: 1) O Cadastro Nacional de Unidades de Conservação - CNUC; 2) O Sistema Nacional de Informações Florestais - SNIF e; 3) O Portal Nacional de Licenciamento Ambiental - PNLA.

O PNLA é uma ferramenta disponibilizada pelo MMA para sistematizar e divulgar informações relacionadas aos procedimentos do licenciamento ambiental e facilitar o acesso pú-

PRACS: Revista Eletrônica de Humanidades do Curso de Ciências Sociais da UNIFAP 
blico em todas as esferas de governo: federal, estadual e municipal. O PNLA tem por objetivo atender à Lei no 10.650, de 16 de abril de 2003, que dispõe sobre o acesso público aos dados e informações ambientais existentes nos órgãos e entidades do Sistema Nacional de Meio Ambiente - SISNAMA.

A plataforma do PNLA foi desenvolvida através de uma parceria entre o MMA e a Universidade Federal de Minas Gerais - UFMG. O portal ainda se apresenta com limitações integrativas de dados, sobretudo dos estados e municípios, possivelmente pelo caráter ainda embrionário de alimentação, ausência de uniformidades de procedimentos e outras dificuldades inerentes a prazos e decisão política colaborativa no âmbito do PNLA.

Uma questão delicada refere-se a casos de corrupção e irregularidades associados a processos de Licenciamento Ambiental no Brasil. Em geral, a ausência de mecanismos de controle social e de transparência na administração pública aumenta as possibilidades de corrupção. Em todo caso, há pressupostos de que a corrupção é consequência da incompatibilidade entre os ritos do Licenciamento Ambiental e o tempo dos negócios, como evidenciado por Serra (2018) ao narrar o licenciamento da barragem da Mineradora Samarco, em MarianaMinas Gerais.

Serra conclui,

A investigação do MPMG sobre o licenciamento da barragem jogou luz sobre o ambiente político-institucional em que megaempreendimentos com potencial poluidor conseguem autorização para funcionar, ignorando ou contornando exigências legais e contando para isso com a complacência e a ineficiência dos que deveriam zelar pela segurança da população e pela proteção ao meio ambiente (2018, p. 124).

A ONG Transparência Brasil divide o combate à corrupção em quatro eixos: 1) Prevenção; 2) Controle Interno; 3) Controle Externo e; 4) Controle Social. A Prevenção envolve reformas institucionais que diminuam as janelas de oportunidade para que a corrupção aconteça. O Controle Interno, a grosso modo, é voltado para ações do próprio Executivo para coibir atos de corrupção. O Controle Externo envolve órgãos fora do Executivo, como Congresso, Tribunais de Contas e Ministérios Públicos. O Controle Social é a sociedade fiscalizando o poder público.

Em complementaridade, a aplicação da Lei de Acesso à Informação - LAI, de 2011, pode jogar luz no que está funcionando e no que não funciona na política ambiental brasileira, facilitando a confiança e o controle social, além de tornar os processos de licenciamento mais céleres, objetivos e eficientes quanto aos resultados do Pós-Licenciamento Ambiental.

Entre as boas práticas adotadas, a Plataforma online de Licenciamento Ambiental desenvolvida pelo Instituto Brasileiro do Meio Ambiente e dos Recursos Naturais Renováveis IBAMA vem disponibilizando dados dos processos em curso (IBAMA, 2019). Esta ferramenta tem atendido, de forma parcial, o direito constitucional de acesso à informação e normas regulamentadoras. Em parte, pelo caráter ainda precário de disponibilização das informações em tempo hábil e atualizações que permitam o acompanhamento célere dos processos pelo público.

A plataforma online foi implantada pelo IBAMA em 2008, sendo batizada de Sistema de Informações sobre o Licenciamento Ambiental - SISLIC. Tem suporte legal na Instrução Normativa no 184/2008, alterada pela Instrução Normativa no 14/2011, que define os procedimentos do Licenciamento Ambiental Federal para maior qualidade, agilidade e transpa- 
rência, prevendo ainda, entre outros, o envolvimento dos órgãos estaduais de meio ambiente.

O SISLIC tem possibilitado o acesso público aos licenciamentos de competência do IBAMA, mas dado à complexidade e volume dos protocolos, ainda demonstra lacunas temporais de informações e mesmo ausências. Uma das questões obscuras é como se dará a migração dos dados entre o SISLIC e o novo Portal Federal (PNLA), a considerar relações programáticas diferenciadas de objetivos e conteúdos.

Fonseca e Resende (2016) realizaram estudos pioneiros sobre as boas práticas de licenciamento ambiental nos estados brasileiros. Os autores demonstraram que os sistemas informatizados apresentam enormes disparidades regionais quanto à funcionalidade e, em termos gerais, ainda estão em estágio embrionário no desenvolvimento de sistemas ágeis, simplificados e informatizados de triagem, escopo, análise, participação social e acompanhamento dos processos.

No caso do órgão estadual do Amapá responsável pelo Licenciamento Ambiental, apesar de dispor de um site institucional (www.imap.ap.gov.br), as boas práticas são classificadas como "raras" ou incipientes por Fonseca e Resende (2016). Ao consultar o site citado verifica-se a inexistência de sistema específico para o instrumento, se resumindo a disponibilizar algumas informações genéricas sobre licenciamento e licenças ambientais.

Como forma de subsidiar um melhor entendimento sobre o Pós-Licenciamento Ambiental aplicado ao estudo de caso proposto neste artigo (hidrelétricas no Amapá), resgata-se os pressupostos que deram origem aos empreendimentos, desde a etapa do inventário até a obtenção da licença de operação.

\section{INVENTÁRIOS HIDRELÉTRICOS: O CASO DO AMAPÁ}

O primeiro inventário hidrelétrico do Amapá teve origem em 16 de dezembro de 1996 com a assinatura do Termo de Convênio entre as Centrais Elétricas do Norte do Brasil S.A ELETRONORTE e o antigo Departamento Nacional de Águas e Energia Elétrica DNAEE, com a interveniência das Centrais Elétricas Brasileiras S.A - ELETROBRÁS e da Secretaria de Infraestrutura do Estado do Amapá. O objetivo do referido convênio foi realizar inventários hidrelétricos nas bacias dos rios Araguari, Cassiporé, Calçoene, Amapá Grande, Tartarugal Grande e Tartarugalzinho (Sub-bacia 30).

O inventário do Rio Araguari foi aprovado pela Agência Nacional de Energia Elétrica ANEEL em 16 de dezembro de 1999; e das demais bacias em 17 de julho de 2000. Na bacia do Rio Araguari foi inventariado seis aproveitamentos hidrelétricos, a saber: 1) Ferreira Gomes; 2) Coaracy Nunes II: 3) Cachoeira Caldeirão; 4) Bambu; 5) Água Branca e; 6) Porto da Serra, totalizando um potencial gerador de $602 \mathrm{MW}$ de energia (Quadro 1). Nos demais rios foram inventariadas 13 pequenas hidrelétricas, com um potencial de cerca de 63 MW de energia. 
Quadro 1 - Hidrelétricas inventariadas no Rio Araguari, Amapá

\begin{tabular}{|c|c|}
\hline Hidrelétrica & Potência \\
\hline Hidrelétrica Ferreira Gomes & $153 \mathrm{MW}$ \\
\hline Hidrelétrica Cachoeira Caldeirão & $134 \mathrm{MW}$ \\
\hline Hidrelétrica Coaracy Nunes II & $104 \mathrm{MW}$ \\
\hline Hidrelétrica Bambu & $84 \mathrm{MW}$ \\
\hline Hidrelétrica Água Branca & $73 \mathrm{MW}$ \\
\hline Hidrelétrica Porto da Serra & $54 \mathrm{MW}$ \\
\hline Total & $\mathbf{6 0 2} \mathbf{M W}$ \\
\hline
\end{tabular}

Fonte: Eletronorte (1999).

As hidrelétricas estudadas foram identificadas e ordenadas levando-se em consideração a viabilidade energética e ambiental dos projetos, como por exemplo, a distância de Unidades de Conservação e a melhor relação potência/reservatório. Sob essas condições, as hidrelétricas Ferreira Gomes e Cachoeira Caldeirão foram as que apresentaram maior viabilidade, seguida pela Coaracy Nunes II. Esta última trata-se da repotenciliazação da usina homônima operada pela Eletronorte desde 1976.

O médio trecho da bacia hidrográfica do Rio Araguari, onde se situam as hidrelétricas, apresenta um desnível de 54,40 metros em $42 \mathrm{~km}$ de extensão, o que resulta num gradiente médio de $1,297 \mathrm{~m} / \mathrm{km}$, indicador bastante atraente para aproveitamentos hidrelétricos.

Com a integração ao Sistema Interligado Nacional - SIN pelo Linhão de Tucuruí, o Amapá tornou-se um estado atrativo para investimentos em hidrelétricas. Assim, a hidrelétrica Ferreira Gomes foi inserida no leilão realizado pela ANEEL em 2010 e a hidrelétrica Cachoeira Caldeirão em 2012, sendo vencidas pelas empresas Alupar e Energia de Portugal - EDP, respectivamente. Entretanto, o Licenciamento Ambiental das hidrelétricas iniciou bem antes do leilão por manifestação de interesse da empresa Odebrecht.

\section{LICENCIAMENTO AMBIENTAL DAS UHES FERREIRA GOMES E CACHOEIRA CALDEIRÃO NO AMAPÁ}

Os processos de Licenciamento Ambiental das hidrelétrica Ferreira Gomes e Cachoeira Caldeirão iniciaram conjuntamente em 01/09/2008 sob os auspícios da Odebrecht, com o protocolo do requerimento de solicitação das respectivas licenças prévias junto ao órgão estadual de meio ambiente do Amapá (Processos SEMA 32.000-1047/2008 e SEMA 32.0001046/2008).

A Odebrecht foi a empresa responsável pelos Estudos de Impactos Ambientais - EIAs que levaram à expedição das licenças prévias dos empreendimentos hidrelétricos. No caso da hidrelétrica Ferreira Gomes, o PBA que deu origem à licença de instalação também foi contratado pela Odebrecht. As licenças prévias dos empreendimentos hidrelétricos foram emitidas pelo órgão ambiental do Amapá em nome da Odebrecht. Contudo, a empresa não participou dos leilões de energia dos respectivos aproveitamentos hidrelétricos.

O Governo do Amapá, a Odebrecht e a população amapaense, sobretudo dos municípios diretamente afetados (Ferreira Gomes e Porto Grande), foram as partes envolvidas no processo de licenciamento prévio das hidrelétricas. As audiências públicas foram realizadas sob a responsabilidade da Odebrecht e cada parte se expôs diante de seus interesses - "relação frente a frente". A desistência da Odebrecht em participar dos leilões da hidrelétricas (Ferreira Gomes e Cachoeira Caldeirão) foi extremamente negativa para a gestão ambiental, uma vez que desconstruiu vínculos objetivos e subjetivos aferidos nas audiências e reuniões. 
O interesse da Odebrecht no leilão da ANEEL, em particular da hidrelétrica Ferreira Gomes, é fato comprovado pela iniciativa antecipada de elaboração do PBA. Mas isso somente aumentou a insegurança do processo de licenciamento ambiental, pois, posteriormente houve a alteração para a titularidade da empresa Alupar, vencedora do leilão. Ou seja, o PBA da hidrelétrica Ferreira Gomes iniciou sob a responsabilidade da Odebrecht e foi "repassado" para a Alupar, salientando a previsão de ressarcimento dos custos, conforme disposto no $\int 3$ o, artigo 28, da Lei Federal no 9.427/1996.

Não se conhece os motivos da desistência da Odebrecht em se habilitar para o leilão das hidrelétricas. Hipóteses apontam para o baixo preço de referências das hidrelétricas aferidos pela ANEEL para o leilão, R\$ 83,00/MWh para a UHEFG e R\$101,00/MWh para a UHECC. Referidos preços não seriam economicamente viáveis, no entendimento da Odebrecht. As empresas Alupar e EDP foram as vencedoras do leilão, com preços ofertados de R\$ 69,82/MWh para a UHEFG e de R \$ 95,31/MWh para a UHECC, respectivamente.

Essa situação é inusitada quanto ao cálculo dos custos socioambientais ${ }^{5}$. É difícil encontrar uma explicação convincente para o fato de uma empresa, que não realizou os estudos de impactos, aferir custos socioambientais. É obvio que estes custos tendem a ser subestimados no orçamento do empreendimento para leilão, ou mesmo estimados com base em modelos, o que aumenta a probabilidade de improvisos e negligências.

Além disso, as empresas apresentam perfil diferenciado quanto às suas práticas de gestão ambiental e de relação com a comunidade. No caso das hidrelétricas Ferreira Gomes e Cachoeira Caldeirão houve reuniões prévias às audiências públicas com a participação de representantes dos empreendimentos e da sociedade civil dos municípios diretamente afetados. Nessas reuniões ocorreram contatos diretos entre a Odebrecht e a população diretamente afetada para aferição de possíveis protocolos de entendimentos. Esses procedimentos não vinculados ao processo de licenciamento foram perdidos pela entrada de outras empresas vencedoras do leilão de geração de energia.

Nesse caso, o aprendizado aponta para a possibilidade de revisão do licenciamento prévio exigido para o leilão de hidrelétricas, de modo a evitar situações como a ocorrida no Amapá e em muitos outros casos similares. Comprovar a viabilidade ambiental de um empreendimento hidrelétrico antes do leilão deve ser uma atribuição da Empresa de Pesquisa Energética - EPE, como previsto na Lei no 10.847/2004, artigo 4o, inciso VI. E isso deve ser feito com bastante antecedência à habilitação ao leilão, de modo que as empresas interessadas possam aferir custos socioambientais mais reais.

Uma alternativa viável seria a regulamentação da Avaliação Ambiental Estratégica - AAE, em substituição da Avaliação Ambiental Integrada ${ }^{6}$, e sua obrigatoriedade de aplicação pelo planejamento governamental, considerando as indicações do Zoneamento Ecológico-

\footnotetext{
5 Os custos socioambientais no orçamento de empreendimentos hidrelétricos são contabilizados pela Conta 10 , que engloba gastos previstos com: (i) aquisição de terrenos e recuperação de obras de infraestrutura resultantes da área inundada; (ii) realocações das populações, inclusive os seus serviços públicos; (iii) mitigação dos efeitos ambientais; e (iv) taxas e outros pagamentos relativos à gestão institucional do processo de licenciamento. Posteriormente, uma outra rubrica relativa aos gastos com estudos e projetos ambientais (17.22.40.54) foi incluída na Conta 17 (BANCO MUNDIAL, 2008).

${ }^{6}$ Considera-se a AAE e a AAI como instrumentos de planejamento ambiental. A AAE é aplicada na avaliação estratégica de políticas, planos e programas com o objetivo de facilitar o diálogo pelo desenvolvimento com sustentabilidade (BANCO MUNDIAL, 2008; PARTIDÁRIO, 2012; SÁNCHEZ, 2017); enquanto a AAI é usada exclusivamente pelo setor hidrelétrico com a finalidade de avaliar os efeitos cumulativos e sinérgicos provocados pelo conjunto de múltiplos aproveitamentos hidrelétricos identificados em determinada bacia hidrográfica (TUCCI; MENDES, 2006).
}

PRACS: Revista Eletrônica de Humanidades do Curso de Ciências Sociais da UNIFAP 
Econômico - ZEE. Nesse caso, a AAE deve atuar no contexto do debate sobre o desenvolvimento, consubstanciado em políticas, planos e programas governamentais, sendo detalhado pelo Estudo de Impacto Ambiental quando se tratar de projeto específico.

No caso das hidrelétricas do Amapá, a exigência de metodologia participativa para elaboração dos PBAs, como condicionante da licença prévia das hidrelétricas, pode ser interpretada como uma medida amenizadora das incertezas e desconfianças geradas pelo regulamento do licenciamento prévio ao leilão de energia (Quadro 2). Diante de novos responsáveis pelos empreendimentos, o PBA participativo pode ser interpretado como a possibilidade de ajustes dos compromissos firmados pela Odebrecht.

Quadro 2 - Condicionantes das licenças prévias das hidrelétricas Ferreira Gomes e Cachoeira Caldeirão aplicado à elaboração participativa do PBA

\begin{tabular}{|l|l|}
\hline \multicolumn{1}{|c|}{ Hidrelétrica } & \multicolumn{1}{c|}{ Condicionante Licença Prévia } \\
\hline Ferreira Gomes & $\begin{array}{l}2.2 \text { - Cada programa do PBA deverá ser construído de forma participativa levando em } \\
\text { consideração os envolvidos nas ações e deverá apresentar nível de detalhamento capaz de } \\
\text { demonstrar a factibilidade de implementação das ações previstas na fase de instalação do } \\
\text { empreendimento. }\end{array}$ \\
\hline Cachoeira Caldeirão & $\begin{array}{l}2.3-\text { O PBA deverá ser elaborado de forma participativa, envolvendo as equipes do } \\
\text { Governo do Estado do Amapá - GEA, das Prefeituras dos municípios atingidos, Ministé- } \\
\text { rio Público e a comunidade local. }\end{array}$ \\
\hline
\end{tabular}

Fonte: Organizado pelo autor.

Os PBAs das hidrelétricas implantadas no Amapá seguiram cronogramas diferenciados. O PBA da hidrelétrica Ferreira Gomes, elaborado sob os auspícios da Odebrecht, foi assumido integralmente e protocolado pela empresa Alupar ${ }^{7}$ no órgão estadual de meio ambiente do Amapá em 2010 e deu origem a duas licenças de instalação em separado: 1å) LI 0267/2010 para implantação do canteiro de obras e utilização das áreas de empréstimo e; 2âa) LI 0278/2010 para implantação de ensecadeira de primeira fase. A licença de instalação definitiva do empreendimento foi emitida em 2011 (LI 056/2011). Este procedimento, apesar de previsto pela Resolução CONAMA 237/97, artigo 9o, indica que o tempo dos negócios exerceu forte influência política no licenciamento do empreendimento.

Já o PBA da hidrelétrica Cachoeira Caldeirão foi elaborado e protocolado pela empresa EDP8 em 2013, tendo a licença de instalação emitida no mesmo ano (LI 556/2013), após embates administrativos entre o empreendedor e o órgão ambiental. A principal divergência se deu pelo Parecer Técnico no 01/2013, elaborado pelo Grupo de Trabalho responsável pela análise técnica do PBA e que fora instituído pelo Ato Conjunto 01/2013 IMAP/SEMA.

O Parecer vinculou a análise do PBA da hidrelétrica Cachoeira Caldeirão a estudos complementares não realizados na etapa de licenciamento prévio. Alegou o Parecer que a ausência desses estudos comprometeria a avaliação dos programas socioambientais, implicando em "insegurança técnica e jurídica quanto à possibilidade de recondicionar as exigências anteriores” (AMAPÁ, 2013). De imediato, houve pedido de reconsideração do empreendedor, ancorado em recurso administrativo formulado pelo advogado Edis Milaré (EDP, 2013), uma das mais respeitadas autoridades em Direito Ambiental do Brasil. Menos de dois meses

${ }^{7}$ A holding Alupar criou em 02/09/2010 a empresa Ferreira Gomes Energia - FGE, passando a ser a responsável pela operação da hidrelétrica Ferreira Gomes, localizada no Rio Araguari, no município de Ferreira Gomes, no estado do Amapá, com potência instalada de $252 \mathrm{MW}$.

8 As empresas EDP e a China Three Gorges - CTG são as responsáveis pela hidrelétrica Cachoeira Caldeirão. Para a construção da obra foi contratada a empresa CESBE S A. - Engenharia e Empreendimentos. 
após o recurso da EDP foi emitida a LI 556/2013, condicionando a apresentação do "PBA - Versão Final”.

A licença de operação da hidrelétrica Ferreira Gomes foi expedida em janeiro de 2013, quatro anos após o início do processo de Licenciamento Ambiental, o que demonstra a sua celeridade processual, possivelmente decorrente da compatibilização das licenças de instalação emitidas por etapas das obras do empreendimento.

Em relação à hidrelétrica Cachoeira Caldeirão, a licença de operação foi emitida somente em 2015, devido ao leilão posterior ao da hidrelétrica Ferreira Gomes e à consequente paralização - "stand by" - dos protocolos de licenciamento pela Odebrecht, para priorização da hidrelétrica Ferreira Gomes, considerada o "filé" das hidrelétricas do Amapá pelos critérios de viabilidade técnico-econômica e ambiental (Quadro 3).

Quadro 3 - Licenças ambientais emitidas para as hidrelétricas Ferreira Gomes e Cachoeira Caldeirão

\begin{tabular}{|l|c|c|}
\hline \multicolumn{1}{|c|}{ Empreendimento/Licença } & UHE Ferreira Gomes & UHE Cachoeira Caldeirão \\
\hline Leilão ANEEL & Leilão 03/2010 & Leilão 06/2012 \\
\hline Licença Prévia & SEMA/IMAP 0040/2010 & SEMA/IMAP 112/2012 \\
\hline Licença de Instalação & SEMA/IMAP 0267/2010 & \\
& SEMA/IMAP 0278/2010 $556 / 2013$ \\
\hline Licença de Operação & SEMA/IMAP 056/2011 & \\
\hline
\end{tabular}

Fonte: Organizado pelo autor.

O prazo entre as licenças prévias e de operação das hidrelétricas Ferreira Gomes e Cachoeira Caldeirão foi de apenas 03 anos. Tempo que pode ser considerado célere diante a média de 6,5 e 9 anos estimados em estudos do Banco Mundial (2008) e do Instituto Acende Brasil (2018), respectivamente.

A celeridade processual do Licenciamento Ambiental das hidrelétricas analisadas coloca o estudo de caso em condição "fora da curva" e instiga a investigar os desdobramentos do Pós-Licenciamento Ambiental, principalmente com relação à emissão das licenças ambientais e das movimentações políticas que levaram à tomada de decisão para a implantação do empreendimento a partir do PBA.

A opção deste estudo pela análise do PBA instrumentaliza a possiblidade de críticas quanto à hipótese de que os empreendimentos concentram suas energias na etapa da licença prévia e negligenciam as subsequentes sob o apelo jurídico do rito processual vinculante, sem preocupações com resultados de médio e longo prazo.

\section{PLANO BÁSICO AMBIENTAL}

O Plano Básico Ambiental - PBA deve ser elaborado segundo orientação metodológica do órgão ambiental responsável pelo processo de licenciamento. O Governo do Amapá não dispõe de termo de referência que instrua a elaboração destes Planos. Os PBAs das hidrelétricas em questão seguiram caminhos e tempos diferenciados de elaboração, respeitadas as condicionantes das licenças prévias, com destaque para a exigência de metodologia participativa.

O PBA é integrado por um conjunto de Programas Socioambientais - PSAs, planejados e estruturados em ações preventivas, mitigadoras e compensatórias dos impactos identificados nas etapas que antecedem a emissão da licença de instalação.

Dessa forma, o esboço de um termo de referência para PBAs deve conter, no mínimo,

PRACS: Revista Eletrônica de Humanidades do Curso de Ciências Sociais da UNIFAP 
uma estrutura lógica que permita seu monitoramento/acompanhamento para a aferição de resultados que possam subsidiar a construção do Plano de Gestão Ambiental.

O acompanhamento e avaliação dos resultados dos PBAs das hidrelétricas estão diretamente vinculados às ações dos PSAs e são assumidas como hipóteses de transparência e de boas práticas de gestão ambiental. Entretanto, não é propósito deste artigo avaliar a fundo os resultados dos PSAs, apesar da existência de lacunas de pesquisas nesse sentido.

Os PSAs e respectivos custos estimados são aqui expostos apenas no sentido de validar a tese do Pós-Licenciamento Ambiental como potencial que facilita, a partir da transição de resultados acumulativos das sucessivas etapas do licenciamento ambiental, a construção do Plano de Gestão Ambiental.

No Quadro 04 são apresentados os PSAs que constam no PBA da hidrelétrica de Ferreira Gomes com seus respectivos custos.

Quadro 4 - Programas Socioambientais do PBA da hidrelétrica Ferreira Gomes

\begin{tabular}{|c|c|}
\hline PSAs do PBA da Usina Hidrelétrica Ferreira Gomes & $\begin{array}{l}\text { Custos Estimados } \\
\text { (R\$) }\end{array}$ \\
\hline \multicolumn{2}{|l|}{ PSAs - Ambientais } \\
\hline Programa de Controle Ambiental das Obras e Construções & $4.500 .000,00$ \\
\hline Programa de Recuperação de Áreas Degradadas - PRAD & $700.000,00$ \\
\hline Projeto de Inventário Florestal do Canteiro e do Reservatório & $165.555,08$ \\
\hline Plano de Resgate da Fauna & $635.302,67$ \\
\hline Plano de Resgate da Ictiofauna & $526.459,20$ \\
\hline Plano de Resgate de Invertebrados Aquáticos & $46.100,00$ \\
\hline Programa de Monitoramento da Qualidade da Água & $953.787,78$ \\
\hline Programa de Monitoramento Hidrossedimentológico & $1.373 .165,36$ \\
\hline Programa de Monitoramento Meteorológico & $253.911,10$ \\
\hline Programa de Monitoramento Sismológico & $209.300,00$ \\
\hline Programa de Monitoramento da Fauna & $1.133 .853,00$ \\
\hline Programa de Monitoramento e Conservação da Ictiofauna & $930.809,00$ \\
\hline Programa de Monitoramento de Invertebrados Aquáticos e Terrestres & $272.260,00$ \\
\hline Programa de Monitoramento de Vetores e Controle da Malária & $2.094 .906,00$ \\
\hline Programa de Monitoramento da Vegetação Terrestre & $496.380,00$ \\
\hline Programa de Monitoramento de Macrófitas Aquáticas & $418.653,00$ \\
\hline Programa de Monitoramento Integrado da Fauna e Flora Terrestres & $43.600,00$ \\
\hline Programa Ambiental de Conservação e Uso do Entorno do Reservatório Artificial - Pacuera & $1.447 .156,00$ \\
\hline Subtotal Programas Ambientais & $16.201 .198,30$ \\
\hline \multicolumn{2}{|l|}{ PSAs - Socioeconômicos } \\
\hline Programa de Indenização de Terras e Benfeitorias & $10.200 .160,00$ \\
\hline Programa de Prospecção e Resgate do Patrimônio Arqueológico & $713.926,40$ \\
\hline Programa de Qualificação de Mão de Obra e Estágio para Jovens & $1.085 .200,00$ \\
\hline Programa de Apoio ao Turismo Sustentável em Ferreira Gomes & $844.736,00$ \\
\hline Programa de Fortalecimento de Fornecedores Locais & $259.200,00$ \\
\hline Programa de Apoio aos Agricultores familiares e Comunidades Ribeirinhas & $497.096,00$ \\
\hline Programa de Apoio a Projetos Esportivos e Culturais & $312.400,00$ \\
\hline Programa de Caracterização e Fomento da Atividade Pesqueira & $428.800,00$ \\
\hline Subtotal Programas Socioeconômicos & $14.341 .518,40$ \\
\hline \multicolumn{2}{|l|}{ PSAs - Programas Institucionais } \\
\hline Programa de Gestão Socioambiental Integrada & $1.037 .070,00$ \\
\hline $\begin{array}{l}\text { Programa de Apoio à Descentralização da Gestão Ambiental nos Municípios de Ferreira Gomes e Porto } \\
\text { Grande }\end{array}$ & $1.500 .000,00$ \\
\hline $\begin{array}{l}\text { Programa de Suporte à Implantação do Comitê da Bacia Hidrográfica do Rio Araguari e do Sistema de Ou- } \\
\text { torga dos Recursos Hídricos }\end{array}$ & $360.000,00$ \\
\hline Programa de Incentivo à Pesquisa & $2.000 .000,00$ \\
\hline Programa de Apoio à Avaliação Estratégica da Bacia do Rio Araguari & $60.000,00$ \\
\hline
\end{tabular}

PRACS: Revista Eletrônica de Humanidades do Curso de Ciências Sociais da UNIFAP 


\begin{tabular}{|c|c|}
\hline Programa de Apoio à Elaboração de Planos Diretores de Ferreira Gomes e Porto Grande & $600.000,00$ \\
\hline Programa de Transferência de Tecnologia em Saneamento para Ferreira Gomes e Porto Grande & $350.358,00$ \\
\hline Programa de Comunicação Social & $2.464 .300,00$ \\
\hline Projeto de Exposição Itinerante & $266.983,00$ \\
\hline Subtotal Programas Institucionais & $8.638 .711,00$ \\
\hline \multicolumn{2}{|l|}{ PSAs - Estudos Complementares } \\
\hline Prospecção de Novas Alternativas para o Desenvolvimento de Ferreira Gomes e Porto Grande & Sem dados \\
\hline Avaliação de Impacto Sobre a Infraestrutura Social e Produtiva & Sem dados \\
\hline Total Geral & $39.181 .427,70$ \\
\hline
\end{tabular}

Fonte: Elaborado pelos autores com base em Ecotumucumaque (2010).

Os custos estimados de investimentos nos PSAs da hidrelétrica Ferreira Gomes foram da ordem de 39 milhões de reais ${ }^{9}$. Os meios de acompanhamento e verificação dos resultados dos PSAs devem integrar a estrutura dos programas em itens específicos. Os PSAs não contêm referido item, com alguns indicando apenas que serão enviados relatórios ao órgão ambiental responsável pelo licenciamento.

Outra importante informação para aferir a validação dos PSAs é o cumprimento da condicionante 2.2 da licença prévia que versa sobre adoção de metodologia participativa na elaboração dos programas. Os PSAs não apresentam detalhamento que possa verificar o cumprimento da condicionante, com alguns se reportando apenas à forma participativa de divulgação de resultados.

Em termos específicos, dois PSAs institucionais apresentam ações propositivas voltadas para transparência e boas práticas de gestão que possibilitam o acompanhamento e a avaliação dos resultados do PBA da hidrelétrica Ferreira Gomes, sendo eles: 1) Programa de Gestão Socioambiental Integrada - PGSI e; 2o) Programa de Comunicação Social - PCS.

O PGSI foi proposto com objetivo de montar uma equipe para gerenciamento ambiental do PBA, de modo a estabelecer e controlar o fluxo de informações para o público interno e externo em articulação com o PCS (ECOTUMUCUMAQUE, 2010). No site da empresa Ferreira Gomes Energia é possível encontrar relatórios periódicos dos programas. Não há informação que se possa avaliar o cumprimento do PGSI, somente citação de que "a empresa mantém o site periodicamente atualizado" (FGE, 2019).

Com relação ao PCS foram previstas três linhas de ações: $1^{a}$ ) Centro de Informações; $2^{a}$ ) Publicação sobre o Empreendimento; $3^{a}$ ) Relatório de Sustentabilidade. Segundo os relatórios constantes no site da empresa, essas ações foram realizadas com os devidos ajustes inerentes à rotina local, com ações que se confundem entre a comunicação dos PSAs e atividades filantrópicas. Particular atenção é a edição única do Relatório de Sustentabilidade, previsto no PCS para ser estruturado no modelo Global Reporting Initiative - GRI. Em 2011, a empresa Ferreira Gomes Energia publicou a única versão do Relatório de Sustentabilidade, com pouco significado para o acompanhamento e avaliação dos resultados do PBA.

No Quadro 5 consta a cronologia dos relatórios contendo informações sistematizadas sobre os PSAs, disponibilizadas no site da empresa Ferreira Gomes Energia.

\footnotetext{
${ }^{9}$ Não estão orçados os custos com aquisição de terras e benfeitorias, que representam o maior volume de recursos da Conta 10 do Orçamento Padrão Eletrobrás - OPE.
} 
Quadro 5 - Relatórios dos PSAs da hidrelétrica Ferreira Gomes

\begin{tabular}{|c|c|c|}
\hline Data & Informação & Conteúdo \\
\hline $10 / 06 / 2011$ & $\begin{array}{l}\text { Relatório Trimestral } \\
\text { Junho } 2011\end{array}$ & $\begin{array}{l}\text { Relatório com informações sobre o andamento de } 38 \text { Programas do PBA. Não informa } \\
\text { a estruturação da equipe prevista no PGSI. Apresenta informações sobre o Centro de } \\
\text { Informações previsto no PCS. }\end{array}$ \\
\hline $10 / 09 / 2011$ & $\begin{array}{l}\text { Relatório Trimestral } \\
\text { Setembro } 2011\end{array}$ & $\begin{array}{l}\text { Relatório com informações sobre o andamento de } 38 \text { Programas do PBA. Não informa } \\
\text { a estruturação da equipe prevista no PGSI. Apresenta informações sobre atividades do } \\
\text { Centro de Informações previsto no PCS. }\end{array}$ \\
\hline $10 / 12 / 2011$ & $\begin{array}{l}\text { Relatório Trimestral } \\
\text { Dezembro } 2011\end{array}$ & $\begin{array}{l}\text { Relatório com informações sobre o andamento de } 38 \text { Programas do PBA. Não informa } \\
\text { a estruturação da equipe prevista no PGSI. Apresenta informações sobre atividades do } \\
\text { Centro de Informações previsto no PCS. }\end{array}$ \\
\hline $10 / 03 / 2012$ & $\begin{array}{l}\text { Relatório Trimestral } \\
\text { Março } 2012\end{array}$ & Relatório sem sumário com informações sobre alguns Programas do PBA. \\
\hline $10 / 04 / 2012$ & $\begin{array}{l}\text { Relatório Mensal } \\
\text { Abril } 2012\end{array}$ & $\begin{array}{l}\text { Relatório com informações sobre o andamento de } 38 \text { Programas do PBA. Não informa } \\
\text { a estruturação da equipe prevista no PGSI. Informa que a empresa estará criando um } \\
\text { site. Apresenta informações sobre atividades do Centro de Informações e de outras } \\
\text { estratégias de comunicação previstas no PCS. }\end{array}$ \\
\hline $10 / 05 / 2012$ & $\begin{array}{l}\text { Relatório Mensal } \\
\text { Maio } 2012\end{array}$ & $\begin{array}{l}\text { Relatório com informações sobre o andamento de } 38 \text { Programas do PBA. Não informa } \\
\text { a estruturação da equipe prevista no PGSI. Informa que contratou uma empresa para } \\
\text { criação de um site. Apresenta informações sobre atividades do Centro de Informações e } \\
\text { de outras estratégias de comunicação previstas no PCS, como a preparação de uma "Van } \\
\text { Itinerante". }\end{array}$ \\
\hline $10 / 07 / 2012$ & $\begin{array}{l}\text { Relatório Mensal } \\
\text { Julho } 2012\end{array}$ & $\begin{array}{l}\text { Relatório com informações sobre o andamento de } 38 \text { Programas do PBA. Não informa } \\
\text { a estruturação da equipe prevista no PGSI. Informa que contratou uma empresa para } \\
\text { criação de um site. Apresenta informações sobre atividades do Centro de Informações e } \\
\text { de outras estratégias de comunicação previstas no PCS, como a preparação de uma "Van } \\
\text { Itinerante". }\end{array}$ \\
\hline $10 / 08 / 2012$ & $\begin{array}{l}\text { Relatório Mensal } \\
\text { Agosto } 2012\end{array}$ & $\begin{array}{l}\text { Relatório com informações sobre o andamento de } 38 \text { Programas do PBA. Não informa } \\
\text { a estruturação da equipe prevista no PGSI. Informa que criou um site. Apresenta infor- } \\
\text { mações sobre atividades do Centro de Informações e de outras estratégias de comunica- } \\
\text { ção previstas no PCS, como a preparação de uma "Van Itinerante". }\end{array}$ \\
\hline $10 / 10 / 2012$ & $\begin{array}{l}\text { Relatório Mensal } \\
\text { Outubro } 2012\end{array}$ & $\begin{array}{l}\text { Relatório com informações sobre o andamento de } 38 \text { Programas do PBA. Não informa } \\
\text { a estruturação da equipe prevista no PGSI. Informa que o site está disponível na inter- } \\
\text { net. Apresenta informações sobre atividades do Centro de Informações e de outras } \\
\text { estratégias de comunicação previstas no PCS, como a preparação de uma "Van Itineran- } \\
\text { te". Cita o Relatório de Sustentabilidade, mas sem data para publicação. }\end{array}$ \\
\hline $10 / 11 / 2012$ & $\begin{array}{l}\text { Relatório Mensal } \\
\text { Novembro } 2012\end{array}$ & $\begin{array}{l}\text { Relatório com informações sobre o andamento de } 38 \text { Programas do PBA. Não informa } \\
\text { a estruturação da equipe prevista no PGSI. Informa que o site está disponível na inter- } \\
\text { net. Apresenta informações sobre atividades do Centro de Informações e de outras } \\
\text { estratégias de comunicação previstas no PCS, como a preparação de uma "Van Itineran- } \\
\text { te". Cita que iniciou a coleta de informações para elaboração do } 1^{\circ} \text { Relatório de Susten- } \\
\text { tabilidade versão } 2011 \text {, com previsão de divulgação em dezembro de } 2012 \text {. }\end{array}$ \\
\hline $10 / 01 / 2013$ & $\begin{array}{l}\text { Relatório Mensal } \\
\text { Janeiro } 2013\end{array}$ & $\begin{array}{l}\text { Relatório com informações sobre o andamento de } 39 \text { Programas do PBA. Sobre o PGSI } \\
\text { faz referência ao site da empresa. Faz referência às seguintes ações do PCS: Van itineran- } \\
\text { te, jornal informativo, Relatório de Sustentabilidade (em fase final de revisão) e Revista } \\
\text { anual "Nossa Energia 2012". }\end{array}$ \\
\hline $10 / 02 / 2013$ & $\begin{array}{l}\text { Relatório Mensal } \\
\text { Fevereiro } 2013\end{array}$ & $\begin{array}{l}\text { Relatório com informações sobre o andamento de } 39 \text { Programas do PBA. Sobre o PGSI } \\
\text { faz referência ao site da empresa. Faz referência às seguintes ações do PCS: Van itineran- } \\
\text { te, jornal informativo, Relatório de Sustentabilidade } 2011 \text { (concluído) e início da versão } \\
2012 \text { e Revista anual "Nossa Energia 2012". }\end{array}$ \\
\hline $10 / 03 / 2013$ & $\begin{array}{l}\text { Relatório Mensal } \\
\text { Março } 2013\end{array}$ & $\begin{array}{l}\text { Relatório com informações sobre o andamento de } 39 \text { Programas do PBA. Sobre o PGSI } \\
\text { faz referência ao site da empresa. Faz referência às seguintes ações do PCS: Van itineran- } \\
\text { te, jornal informativo, Relatório de Sustentabilidade } 2011 \text { (concluído) e início da versão } \\
\text { 2012, Revista anual "Nossa Energia 2012". }\end{array}$ \\
\hline $15 / 07 / 2013$ & $\begin{array}{l}8^{\circ} \text { Relatório Trimes- } \\
\text { tral de Meio Ambien- } \\
\text { te Junho } 2013\end{array}$ & $\begin{array}{l}\text { Relatório com informações sobre o andamento de } 39 \text { Programas do PBA. Sobre o PGSI } \\
\text { faz referência ao site da empresa. Faz referência às seguintes ações do PCS: } 1^{\circ} \text { Relatório } \\
\text { de Sustentabilidade } 2011 \text { (concluído), Revista anual "Nossa Energia 2012". Centro de } \\
\text { informação e Van itinerante. }\end{array}$ \\
\hline $30 / 09 / 2013$ & $\begin{array}{l}9^{\circ} \text { Relatório Trimes- } \\
\text { tral de Meio Ambien- } \\
\text { te Setembro } 2013\end{array}$ & $\begin{array}{l}\text { Relatório com informações sobre o andamento de } 39 \text { Programas do PBA. Sobre o PGSI } \\
\text { faz referência ao site da empresa. Faz referência às seguintes ações do PCS: Informativo } \\
\text { "+Energia", Revista Anual "Nossa Energia", } 2^{\circ} \text { Relatório de sustentabilidade da FGE, } \\
\text { Van Itinerante, Centro de informação, entre outras. }\end{array}$ \\
\hline $15 / 12 / 2013$ & $\begin{array}{l}10^{\circ} \text { Relatório Trimes- } \\
\text { tral de Meio Ambien- } \\
\text { te Dezembro } 2013\end{array}$ & $\begin{array}{l}\text { Relatório com informações sobre o andamento de } 39 \text { Programas do PBA. Sobre o PGSI } \\
\text { faz referência ao site da empresa. Faz referência às seguintes ações do PCS: Informativo } \\
\text { "+Energia", Revista Anual "Nossa Energia", } 2^{\circ} \text { Relatório de sustentabilidade da FGE, }\end{array}$ \\
\hline
\end{tabular}

PRACS: Revista Eletrônica de Humanidades do Curso de Ciências Sociais da UNIFAP 


\begin{tabular}{|l|l|l|}
\hline & \multicolumn{1}{|c|}{} & Van Itinerante, Centro de informação, entre outras. \\
\hline $15 / 03 / 2014$ & $\begin{array}{l}11^{\circ} \text { Relatório Trimes- } \\
\text { tral de Meio Ambien- } \\
\text { te Março 2014 }\end{array}$ & $\begin{array}{l}\text { Relatório com informações sobre o andamento de 39 Programas do PBA. Sobre o PGSI } \\
\text { faz referência ao site da empresa. Comunica que as ações do PCS continuam sendo } \\
\text { executadas. }\end{array}$ \\
\hline $04 / 02 / 2015$ & $\begin{array}{l}1^{\circ} \text { Relatório Semestral } \\
\text { UHE Ferreira Gomes }\end{array}$ & $\begin{array}{l}\text { Relatório se reporta aos condicionantes da LO. Não apresenta informações sobre o } \\
\text { PGSI e o PCS. }\end{array}$ \\
\hline $08 / 04 / 2016$ & $\begin{array}{l}1^{\circ} \text { Relatório Semestral } \\
2016\end{array}$ & $\begin{array}{l}\text { Relatório se reporta aos condicionantes da LO. Não apresenta informações sobre o } \\
\text { PGSI e o PCS. }\end{array}$ \\
\hline $03 / 08 / 2017$ & $\begin{array}{l}\text { Relatório Semestral } \\
\text { Julho 2017 UHE } \\
\text { Ferreira Gomes }\end{array}$ & $\begin{array}{l}\text { Relatório se reporta aos condicionantes da LO. Não apresenta informações sobre o } \\
\text { PGSI e o PCS. }\end{array}$ \\
\hline
\end{tabular}

Fonte: Organizado pelos autores com base em FGE (2019).

Observa-se um esforço inicial da empresa Ferreira Gomes Energia em gerar informação sobre os programas do PBA, mas com ausência de indicadores de acompanhamento e de avaliação de resultados. O PGSI não foi cumprido quanto à montagem de uma equipe interna de meio ambiente para gerenciar as ações dos PSAs, com inferências de ações direcionadas predominantemente ao site da empresa.

Por sua vez, o PCS que deveria se movimentar de acordo com o PGSI se tornou um programa multitarefas, incluindo as propostas do PBA e ações inerentes à rotina de demandas assistencialistas locais. Faz-se uma crítica quanto à publicação de somente uma edição do Relatório de Sustentabilidade (versão 2011), de pouco significado para o acompanhamento e verificação dos resultados do PBA.

O PBA da hidrelétrica Cachoeira Caldeirão consta de 45 programas, 07 notas técnicas e 04 proposições de estudos complementares (Quadro 6). Não há informação sobre os custos dos PSAs, nem qualquer outro instrumento acessível on-line que possibilite a verificação de boas práticas de gestão ambiental. No site da empresa constam apenas cópias de alguns PSAs e das licenças ambientais (EDP, 2019). Entretanto, pela aferição comparativa com a hidrelétrica Ferreira Gomes e considerando os altos custos para o equacionamento de alguns impactos da hidrelétrica Cachoeira Caldeirão, estima-se que os PSAs alcancem um volume de recursos da ordem de 50 milhões de reais ${ }^{10}$.

Quadro 6 - Programas Socioambientais do PBA da hidrelétrica Cachoeira Caldeirão ${ }^{11}$

\begin{tabular}{|l|}
\hline PSAs - Programas Institucionais \\
\hline Programa de Gerenciamento Socioambiental Integrado \\
\hline Programa de Comunicação Social e Educação Ambiental \\
\hline Programa de Compensação Ambiental \\
\hline Estudo Complementar Sobre Valoração dos Recursos Madeireiros da FLOTA do Amapá \\
\hline Nota Técnica Sobre Afetação da FLOTA do Amapá \\
\hline Nota Técnica Sobre Construção das Sedes do IMAP e SEMA \\
\hline PSAs - Programa de Controle Ambiental das Obras e Construções \\
\hline Programa de Controle Ambiental de Ações Construtivas \\
\hline Programa de Controle da Poluição Durante as Obras \\
\hline Programa de Controle e Monitoramento de Processos Erosivos \\
\hline Programa de Saúde e Segurança nas Obras \\
\hline Programa de Gerenciamento de Riscos e de Ações de Emergência \\
\hline Programa de Oferta de Água Potável à População \\
\hline PSAs - Programas Ambientais - Meio Físico \\
\hline Programa de Monitoramento dos Recursos Hídricos Superficiais \\
\hline
\end{tabular}

10 Não estão orçados os custos com aquisição de terras e benfeitorias, que representam o maior volume de recursos da Conta 10 do Orçamento Padrão Eletrobrás - OPE.

${ }^{11} \mathrm{Na}$ estrutura dos PSAs do Plano Básico Ambiental da UHECC não consta item "custos". 


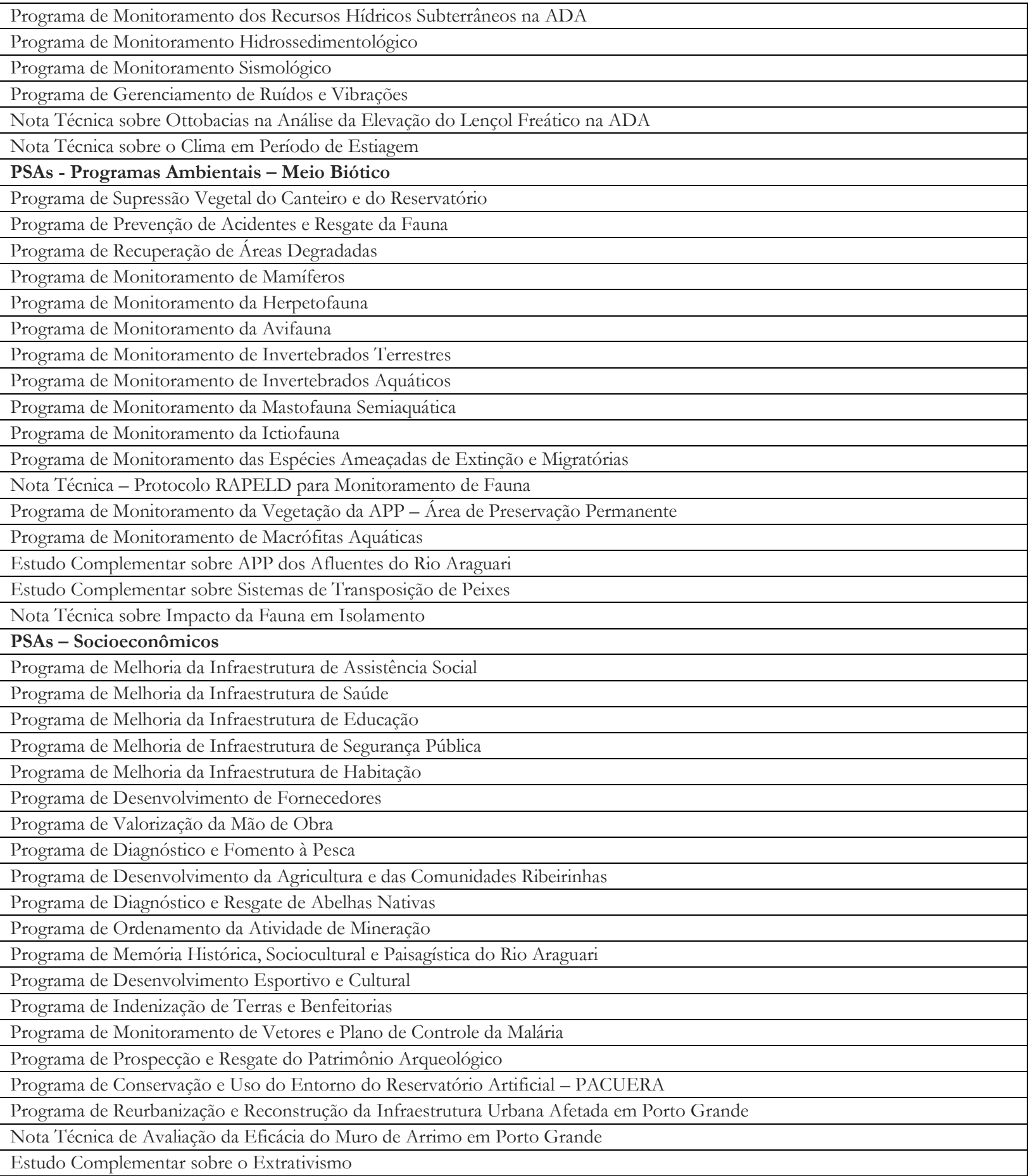

Fonte: Elaborado pelos autores com base Ecotumucumaque (2013).

O portal do Governo do Amapá destaca a construção de um Hospital Regional de Porto Grande, no valor de 11,2 milhões de reais, as dispensas da empresa responsável pela hidrelétrica Cachoeira Caldeirão como compensação pelos impactos da obra (AMAPÁ, 2018). Este fato, não vinculado ao processo de licenciamento ambiental do empreendimento pode responder pela flexibilização do monitoramento e da avaliação dos resultados dos PSAs.

Negociações voluntárias entre governos e empreendedores que contribuam para amenização de problemas sociais na área diretamente afetada, como no caso da saúde e educação, 
são positivas, mas nunca como moeda de troca dos compromissos firmados no processo de Licenciamento Ambiental.

Há registro da criação de Grupos de Trabalhos Interinstitucionais - GTIs no âmbito do Conselho Estadual de Meio Ambiente do Amapá - COEMA/AP com a função de acompanhamento do Licenciamento Ambiental das Hidrelétricas de Ferreira Gomes e Cachoeira Caldeirão. Contudo, os registros do trabalho destes GTIs apresentam descontinuidades e pouca agregação qualitativa ao licenciamento.

Dessa forma e considerando a metodologia proposta neste artigo, torna-se impossível a análise do monitoramento e da avaliação dos resultados dos PSAs da hidrelétrica Cachoeira Caldeirão. Em termos gerais, constata-se o retrocesso de boas práticas de licenciamento em relação à hidrelétrica Ferreira Gomes, com significados que perpassam por questionamentos que sirvam para validar pesquisas futuras, mas também a demonstração das fragilidades das instituições que executam e fiscalizam o cumprimento das normas ambientais no Amapá.

\section{CONCLUSÃO}

O Pós-Licenciamento Ambiental é um conceito que se aplica enquanto entendimento de um processo sinérgico que permite, a partir da transição acumulativa de resultados de boas práticas das sucessivas etapas do licenciamento ambiental (LP, LI e LO), favorecer um ambiente institucional positivo para a construção e implementação de um Plano de Gestão Ambiental.

O referido Plano permite que os impactos de determinada atividade econômica sejam reconhecidos e equacionados em longo prazo, sem as limitações impositivas do tempo cronológico das licenças ambientais. Tem como fundamento o fortalecimento de princípios que regem o discurso do desenvolvimento sustentável, como a transparência e a participação das partes envolvidas e interessadas.

O resultado esperado do Pós-Licenciamento Ambiental é a simplificação do processo de licenciamento, com objetividade e distinção de prioridades definidas em metodologias participativas que reconheçam o que realmente é importante diante da complexidade e das infinitas respostas do meio ambiente em relação aos impactos da atividade econômica.

O estudo de caso das hidrelétricas Ferreira Gomes e Cachoeira Caldeirão, implantadas na bacia do Rio Araguari, no estado do Amapá, mostra que o volume de recursos orçados para a gestão dos impactos ambientais (cerca de 100 milhões de reais) se diluíram nas incertezas das evidências do monitoramento e da avaliação dos resultados.

O licenciamento analisado indica que o instrumento não foi capaz de cumprir seus objetivos, como gerenciar os impactos socioambientais e fomentar sinergias em favor da melhoria contínua do lugar onde os empreendimentos se instalaram. Em pelo menos um dos casos analisados é notório que o processo de gestão ambiental foi anulado diante de acordos exclusos ao licenciamento.

O achado confirma a hipótese de que a fragilidade das instituições de meio ambiente é premeditada como estratégia para acordos políticos pactuados fora dos vínculos processuais do licenciamento e carimbados midiaticamente como compensação pelos impactos gerados, como ficou em suspeição no caso do Hospital Regional de Porto Grande, em construção pela empresa concessionária da hidrelétrica Cachoeira Caldeirão.

Uma questão à parte, mas não menos importante, é o reconhecimento de que o Licenci-

PRACS: Revista Eletrônica de Humanidades do Curso de Ciências Sociais da UNIFAP 
amento Ambiental é um instrumento que vem sendo usado apenas para a legitimação das ações do estado neoliberal, que forja múltiplas camuflagens discursivas para impor o crédulo no desenvolvimento econômico. É inaceitável que as instituições públicas, que deveriam fiscalizar o cumprimento da lei, não se permitam mediar os desequilíbrios do direito em favor dos interesses das populações afetadas.

Finalmente, o conceito de Pós-Licenciamento Ambiental se insere nesse contexto como crítica aos descaminhos do licenciamento e como contribuição a repensar a revisão da política ambiental, centrada não somente em boas práticas de gestão, mas também em princípios institucionais que reconheçam e respeitem o tempo próprio dos lugares, das ecologias e das populações locais.

\section{REFERÊNCIAS}

ALMEIDA, M. R. R.; MONTAÑO, M. A Efetividade dos Sistemas de Avaliação de Impacto Ambiental nos Estados de São Paulo e Minas Gerais. Ambiente e Sociedade, São Paulo, v. XX, n. 2, p. 79-106, abr.-jun. 2017.

AMAPÁ. Instituto do Meio Ambiente e de Ordenamento Territorial do Amapá. Parecer Técnico PBA no 01/2013. Macapá: IEPA, 2013.

AMAPÁ. Iniciam as obras do Hospital Regional de Porto Grande. 2018. Disponível em: https://www.portal.ap.gov.br/noticia/2004/iniciam-as-obras-do-hospital-regional-deporto-grande. Acesso em: 14 jul. 2019.

BANCO MUNDIAL. Licenciamento Ambiental de Empreendimentos Hidrelétricos no Brasil: Uma Contribuição para o Debate. Relatório Principal, 2008.

BARRETO, F. R. M. Análise da etapa de delimitação do escopo em processos de avaliação de impacto ambiental no estado de São Paulo. Dissertação (Mestrado em Ciências da Engenharia Ambiental) - Escola de Engenharia de São Carlos, Universidade de São Paulo, São Carlos, 2012.

BURSZTYN, M. A.; BURSZTYN, M. Fundamentos de Política e Gestão Ambiental: Caminhos para a sustentabilidade. Rio de Janeiro: Garamond, 2012.

CASTRO, E. R. et al. Hidrelétricas na Amazônia e grandes dilemas postos à sociedade no século XXI. Papers do NAEA, no 343, Belém: UFPA/NAEA, dezembro 2014.

CHAGAS, M. A.; SANTOS, E. S.; CUNHA, A. C. Alguém viu a Pororoca por aí? In: XXI Simpósio Brasileiro de Recursos Hídricos, 2015. Brasília. Anais... Brasília, DF, 2015.

DOWBOR, L. Informação para a cidadania e o desenvolvimento sustentável. 2004. Disponível em: http://dowbor.org/2004/10/informacao-para-a-cidadania-e-o-desenvolvi mento-sustentavel-2.html/. Acesso em: 28 nov. 2018.

ECOTUMUCUMAQUE. Plano Básico Ambiental da UHE Ferreira Gomes. Macapá, 2010.

ECOTUMUCUMAQUE. Plano Básico Ambiental da UHE Cachoeira Caldeirão. Macapá, 2013.

EDP - Energia de Portugal. Pedido de Reconsideração/Recurso Administrativo em relação ao Parecer Técnico PBA no 01/2013. São Paulo: EDP Energias do Brasil S.A., 2013. EDP - Energia de Portugal. UHE Cachoeira Caldeirão. Meio Ambiente. Disponível em: https://uhecachoeiracaldeirao.com.br/pt-br/meio-ambiente/programas. Acesso em: 14 jul. 2019. 
FEARNSIDE, P. M. Hidrelétricas na Amazônia: impactos ambientais e sociais na tomada de decisões sobre grandes obras. Manaus: Editora do INPA, volumes 1 e 2, 2015.

FEARNSIDE, P. M. Hidrelétricas na Amazônia brasileira: questões ambientais e sociais. In: FLORIANI, D.; HEVIA, A. E. (orgs.). América Latina: Sociedade e Meio Ambiente: teorias, retóricas e conflitos em desenvolvimento. Curitiba: Editora da UFPR, 2016, p. 289-316.

FGE - Ferreira Gomes Energia. Relatórios. Disponível em: http://ferreiragomesenergia. com.br/relatorios/. Acesso em: 22 jun. 2019.

FONSECA, A.; RESENDE, L. Boas práticas de transparência, informatização e comunicação social no licenciamento ambiental brasileiro: uma análise comparada dos websites dos órgãos licenciadores estaduais. Engenharia Sanitária e Ambiental, Rio de Janeiro, vol. 21, n. 2, p. 295-306, abr./jun. 2016.

FONSECA, A. et al. Nota Técnica - Projeto de Lei Geral do Licenciamento Ambiental: análise crítica e propositiva do projeto de lei à luz das boas práticas internacionais e da literatura científica. Waterloo (Canadá): School of Environment, Resources and Sustainability/University of Waterloo, 2019. Disponível em: http:/ / avaliacaodeimpacto.org.br. Acesso em: 11 jul. 2019.

IBAMA - Instituto Brasileiro do Meio Ambiente e dos Recursos Naturais Renováveis. Sistema Informatizado de Licenciamento Ambiental Federal. Disponível em: https://servicos.ibama.gov.br/licenciamento/. Acesso em: 06 mar. 2019.

IMAP - Instituto do Meio Ambiente e de Ordenamento Territorial do Amapá. Licenças. Disponível em: http://www.imap.ap.gov.br/licencas. Acesso em: 05 mar. 2019.

Instituto Acende Brasil. Licenciamento Ambiental: equilíbrio entre precaução e eficiência. White Paper 21, São Paulo, 2018. 36 p.

MMA - Ministério do Meio Ambiente. Plano de Dados Abertos 2017/2018. Brasília: Ministério do Meio Ambiente, 2017. Disponível em: http://www.ambiente.gov.br/informa coes-ambientais/plano-de-dados-abertos.html. Acesso em: 29 nov. 2018.

PARTIDÁRIO, M. R. Guia de melhores práticas para Avaliação Ambiental Estratégica. Lisboa: Agência Portuguesa do Ambiente, 2012.

RIBEIRO, J. C. J. (Org.). Licenciamento Ambiental: Herói, Vilão ou Vítima. Belo Horizonte: Arraes Editores, 2015.

SÁNCHEZ, L. H. Avaliação de impacto ambiental: Conceitos e métodos. 2 ed. São Paulo: Oficina de Textos, 2013.

SÁNCHEZ, L. E. Por que não avança a avaliação estratégica no Brasil. Estudos Avançados, São Paulo, vol. 31, n. 89, Jan./Apr. 2017.

SANTOS, V. F. dos. Ambientes Costeiros Amazônicos: Avaliação de Modificações por Sensoriamento Remoto. (Doutorado em Ciências) - Centro de Geociências. Universidade Federal Fluminense, Niterói, 2006.

SANTOS, E. S. dos. Modelagem Hidrodinâmica e Qualidade da Água em Região de Pororoca na Foz do Rio Araguari-AP. (Mestrado em Biodiversidade Tropical) - Universidade Federal do Amapá, Macapá, 2012.

SANTOS, E. S.; CUNHA, A. C.; CUNHA, H. F. A. Hydroelectric Power Plant in the Amazon and Socioeconomic Impacts on Fishermen in Ferreira Gomes County- Amapá State. Ambiente e Sociedade, São Paulo, v. 20, n. 4, 2017.

SEN, A. Desenvolvimento como Liberdade. São Paulo: Companhia das Letras, 2010.

SERRA, C. Tragédia em Mariana: a história do maior desastre ambiental do Brasil. Rio de 
Janeiro: Record, 2018.

TUCCI, C. E. M.; MENDES, C. A. Avaliação Ambiental Integrada de Bacia Hidrográfica. Ministério do Meio Ambiente. Secretaria de Qualidade Ambiental. Brasília: MMA, 2006. 